\title{
Results from the 5-year, phase IV RENEW (Registry to Evaluate Novantrone Effects in Worsening Multiple Sclerosis) study
}

\author{
Victor M Rivera ${ }^{1 *}$, Douglas R Jeffery ${ }^{2}$, Bianca Weinstock-Guttman ${ }^{3}$, Daena Bock ${ }^{4}$ and Fernando Dangond ${ }^{4}$
}

\begin{abstract}
Background: Registry to Evaluate Novantrone Effects in Worsening Multiple Sclerosis (RENEW) was a 5-year, phase IV study in which the safety of Mitoxantrone was monitored in a patient cohort from the United States (US). The objective of the study was to evaluate the long-term safety profile of Mitoxantrone in patients with secondary progressive multiple sclerosis (SPMS), progressive relapsing multiple sclerosis (PRMS), and worsening relapsing-remitting multiple sclerosis (RRMS).

Methods: Overall, 509 patients (395 SPMS, 81 worsening RRMS, 33 PRMS) were enrolled and treated at 46 multiple sclerosis (MS) treatment centers located in the US. Patients received Mitoxantrone in accordance with the package insert every 3 months. During the treatment phase, patients received laboratory workups and cardiac monitoring every 3 months and then annually for a total of 5 years.

Results: Five hundred and nine subjects were enrolled in this trial and received at least one infusion of Mitoxantrone. Overall, 172 (33.8\%) completed the 5-year trial (i.e., participated for 5 years \pm 3 months [treatment + follow-up]); 337 (66.2\%) did not complete the 5-year trial. Annual follow-up data were available for 250 of 509 enrolled patients. Left ventricular ejection fraction reduction under 50\% was reported in 27 (5.3\%) patients during the treatment phase $(n=509)$ and $14(5.6 \%)$ patients during the annual follow-up phase $(n=250)$. Signs and symptoms of congestive heart failure were observed in 10 (2.0\%) patients (six during treatment phase and four during the annual follow-up phase). Post-hoc analyses of the risk for cardiotoxicity outcomes revealed that cumulative dose exposure is the primary risk factor associated with the risk of cardiac toxicity with Mitoxantrone. Therapy-related leukemia was reported in three (0.6\%) patients who received total cumulative Mitoxantrone doses of $73.5 \mathrm{mg} / \mathrm{m}^{2}, 107.3 \mathrm{mg} / \mathrm{m}^{2}$, and $97.1 \mathrm{mg} / \mathrm{m}^{2}$ respectively. During the treatment phase, persistent amenorrhea developed in 22\% (28/128) of women with regular menses and 51\% (25/49) of women with irregular menses at baseline. During the annual follow-up phase, persistent amenorrhea developed in 5\% (4/73) of women with regular menses at baseline.
\end{abstract}

Conclusion: RENEW results are consistent with the known safety profile of Mitoxantrone, and provide additional long-term safety data for Mitoxantrone in MS patients.

\section{Background}

Mitoxantrone is a synthetic anthracenedione agent originally developed for the treatment of cancer. Subsequent preclinical studies also demonstrated the immunosuppressive properties of Mitoxantrone [1-3], which eventually led to its clinical investigation in patients with multiple sclerosis (MS) $[4,5]$. Based on efficacy and safety results from two randomized clinical trials [4,5], Mitoxantrone

\footnotetext{
* Correspondence: vrivera@bcm.edu

'Baylor College of Medicine, Houston, TX, USA

Full list of author information is available at the end of the article
}

was approved for the treatment of secondary progressive MS (SPMS), progressive relapsing MS (PRMS), and worsening relapsing-remitting MS (RRMS) in the United States (US) and Europe.

The use of Mitoxantrone in patients with MS, however, is associated with significant risks that include, among the more serious concerns, cardiotoxicity [6-15], treatmentrelated leukemia [16-32], and amenorrhea [33]. At present, the risk factors contributing to these toxicities are not completely understood. The main objective of the current report is to present the long-term safety data from the

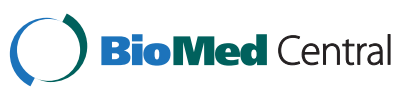


Registry to Evaluate Novantrone Effects in Worsening Multiple Sclerosis (RENEW) Study. Results from this phase IV study provide additional data on the long-term safety of Mitoxantrone in MS patients, and offer some insight into the risk factors underlying the development of Mitoxantrone-related toxicities.

\section{Methods}

\section{Study design}

RENEW was a multicenter, prospective, open-label, observational phase IV study monitoring the safety and tolerability of Mitoxantrone. From 17 October 2000 until 15 July 2008, 509 patients were enrolled and treated at 46 MS treatment centers located in the US.

Patients aged 18-65 years with clinically defined or a laboratory-supported diagnosis of SPMS, PRMS, or worsening RRMS were included in the study if they had a platelet count in excess of 100,000 cells $/ \mu \mathrm{L}$ and a granulocyte count in excess of 2,000 cells $/ \mu \mathrm{L}$. Patients were excluded from the study if they presented with cardiac risk factors, including a history of congestive heart failure (CHF) or left ventricular ejection fraction (LVEF) $<50 \%$ of normal.

Patients were treated with commercially available Mitoxantrone in accordance with the package insert (i.e., $12 \mathrm{mg} / \mathrm{m}^{2}$ as a 5-15 minute intravenous [IV] infusion). Doses were administered approximately every 3 months until a cumulative dose of $140 \mathrm{mg} / \mathrm{m}^{2}$ was reached, unless the patient or physician chose to discontinue or interrupt therapy or there was an adverse event (AE) that prevented further therapy. All enrolled patients, regardless of duration of therapy, were to be followed until the end of their 5-year trial participation period.

All participating investigators obtained local institutional review board approval prior to their initiation of the study, and all patients provided written informed consent before enrolment.

This study was conducted in compliance with the ethical principles enunciated in the World Medical Association's Declaration of Helsinki, Ethical Principles for Medical Research Involving Human Subjects.

\section{Study assessments}

Patients were medically evaluated before treatment initiation, including the assessment of their Expanded Disability Status Scale (EDSS) score. Patients were assessed every 3 months during the treatment phase and then annually, for a total of 5 years. All enrolled subjects were to be followed to the end of their 5-year trial participation period.

Cardiovascular endpoints included LVEF (measured using echocardiogram or a multiple gated acquisition scan), symptoms of CHF, and cardiac-related serious AEs (SAEs). Assessments of LVEF and CHF were performed at baseline, before each infusion, and annually after treatment discontinuation or completion; SAEs were reported as they occurred.

At baseline, women were classified as having regular, irregular, or absent menses. Women with regular or irregular menses were monitored for the development of on-study persistent amenorrhea (defined as the absence of menses on at least two consecutive treatment visits that did not subsequently return during the course of the study) or transient amenorrhea (resumption of menses after absence on $\geq 2$ consecutive treatment visits). Women with absent menses at baseline were monitored for resumption of menses ( $\geq 1$ report of menses on-study).

\section{Statistical methods}

Demographic, baseline, cumulative dose, and LVEF data were summarized by type of MS using descriptive statistics. Frequencies with 95\% confidence intervals (CIs) were used to evaluate the incidence of SAEs, symptomatic CHF, abnormal LVEF $(<50 \%)$, and serious infections. The incidence of clinical relapses, skipped and missed doses, abnormal laboratory values and concomitant medications were also summarized. For female patients, menstrual status was tabulated (regular, irregular, absent).

\section{Post-hoc analyses}

To assess the factors potentially contributing to cardiotoxicity, post-hoc analyses were conducted in all patients receiving Mitoxantrone alone or concomitantly with other medications during the RENEW study. Patients with and without cardiac events were included in the analysis. Presence of cardiac events was defined as LVEF $<50 \%$, clinically significant drop in LVEF as indicated by a $10 \%$ decrease from baseline, cardiac SAE, or signs or symptoms of $\mathrm{CHF}$ requiring hospitalization or other treatment.

Poisson and logistic regression models were used to determine the significance of the effects of potential contributing factors on cardiotoxicity risk. A Fisher's exact test was used to evaluate the effects of concomitant medication.

\section{Results}

\section{Study cohort}

Demographics, baseline characteristics, and study completion statistics for RENEW are shown in Table 1. Data were available for all 509 patients during the treatment phase. Long-term follow-up data were available for 250 (49\%) patients (not all patients in the follow-up phase completed the study). In general, the majority of patients were female (67.6\%); mean age at baseline was 46 years (range 19-68). Most patients $(77.6 \%)$ were diagnosed with SPMS. The mean baseline LVEF was $62 \%$. Median baseline EDSS score was 6 (range 0-9) and median times since onset of MS and MS diagnosis were 11.8 years (range 0.4-45.3) and 8.6 years $(0.0-39.9)$, respectively. 
Table 1 Patient characteristics

\begin{tabular}{|c|c|c|c|c|}
\hline Characteristic & Overall & $\begin{array}{c}\text { Worsening } \\
\text { RRMS }\end{array}$ & \multicolumn{2}{|c|}{ RRMS } \\
\hline \multicolumn{5}{|l|}{ At baseline } \\
\hline Patients enrolled, ${ }^{\mathrm{a}} \mathrm{n}(\%)$ & $509(100.0)$ & $81(15.9)$ & $33(6.5)$ & $395(77.6)$ \\
\hline Mean age, years (range) & $46(19-68)$ & $40(19-63)$ & $47(30-64)$ & $47(25-68)$ \\
\hline Women,\% & 67.6 & 77.8 & 54.5 & 66.6 \\
\hline White,\% & 88.6 & 85.2 & 87.9 & 89.4 \\
\hline History of MS, $n$ & 506 & 80 & 32 & 394 \\
\hline Median EDSS score (range) & $6.0(0.0-9.0)$ & $4(1.0-8.0)$ & $6.0(1.5-8.5)$ & $6.5(0.0-9.0)$ \\
\hline Median years since onset (range) & $11.8(0.4-45.3)$ & $8.0(0.4-29.2)$ & $11.5(0.6-34.5)$ & $13.0(0.6-45.3)$ \\
\hline Median years since diagnosis (range) & $8.6(0.0-39.9)$ & $4.8(0.0-24.6)$ & $7.3(0.1-26.5)$ & $9.3(0.1-39.9)$ \\
\hline Median years since most recent relapse (range) & $0.4(0.0-20.3)$ & $0.2(0.0-2.4)$ & $0.2(0.0-4.6)$ & $0.5(0.0-20.3)$ \\
\hline Patients with no prior treatment for MS, n (\%) & $16(3.1)$ & $3(3.7)$ & $2(6.1)$ & $11(2.8)$ \\
\hline Women with regular menses, $\mathrm{n}(\%)$ & $128(37.2)$ & $34(54.0)$ & $7(38.9)$ & $87(33.1)$ \\
\hline Cardiac, $\mathbf{n}$ & 505 & 81 & 32 & 392 \\
\hline Mean LVEF,\% (range) & $62(50-83)$ & $62(50-83)$ & $63(52-79)$ & $62(50-83)$ \\
\hline Study completion, $n$ & 509 & 81 & 33 & 395 \\
\hline Patients who did not complete & $486(95.5)$ & $74(91.4)$ & $32(97.0)$ & $380(96.2)$ \\
\hline \multicolumn{5}{|l|}{ Mitoxantrone treatment, ${ }^{\mathrm{b}} \mathrm{n}(\%)$} \\
\hline Did not complete 5-year study, ${ }^{c}$ (\%) & $320(62.9)$ & $46(56.8)$ & $27(81.8)$ & $247(62.5)$ \\
\hline Completed 5-year study, $\mathrm{c}(\%)$ & $166(32.6)$ & $28(34.6)$ & $5(15.2)$ & $133(33.7)$ \\
\hline Patients who completed & $23(4.5)$ & $7(8.6)$ & $1(3.0)$ & $15(3.8)$ \\
\hline \multicolumn{5}{|l|}{ Mitoxantrone treatment, ${ }^{\mathrm{b}} \mathrm{n}(\%)$} \\
\hline Did not complete 5-year study, ${ }^{\mathrm{C}} \mathrm{n}(\%)$ & $17(3.3)$ & $5(6.2)$ & $1(3.0)$ & $11(2.8)$ \\
\hline Completed 5-year study, ${ }^{c} \mathrm{n}(\%)$ & $6(1.2)$ & $2(2.5)$ & $0(0)$ & $4(1.0)$ \\
\hline
\end{tabular}

EDSS=Expanded Disability Status Scale; LVEF=left ventricular ejection fraction;MS=multiple sclerosis; PRMS=progressive relapsing multiple sclerosis; RENEW=Registry to Evaluate Novantrone Effects in Worsening Multiple Sclerosis; RRMS=relapsing remitting multiple sclerosis; SPMS=secondary progressive multiple sclerosis.

${ }^{\text {a }}$ Patients with validated data who have received at least one dose of Mitoxantrone.

${ }^{b}$ Patients reaching a cumulative dose of $132 \mathrm{mg} / \mathrm{m}^{2}$ or greater are considered to have completed treatment.

cPatients participating in the study for 5 years \pm 3 months are considered to have completed RENEW.

Overall, $172(33.8 \%)$ patients completed the RENEW study. Of these patients, six (1.2\%) completed full treatment with Mitoxantrone (i.e., reached a cumulative dose of $132 \mathrm{mg} / \mathrm{m}^{2}$ or greater) while $166(32.6 \%)$ patients did not. The mean duration of Mitoxantrone therapy was 1.5 years (range 0.0-4.9 years). The majority of subjects were in the trial for over 42 months $(n=263,51.7 \%)$ while $57(11.2 \%)$ patients were in the study for $\leq 12$ months. The mean cumulative dose per patient was $69.8 \mathrm{mg} / \mathrm{m}^{2}$ (range 8.0$148.6 \mathrm{mg} / \mathrm{m}^{2}$ ). Patients received a mean of six infusions (range 1-18 infusions) during the study period (Figure 1). Doses $<10 \mathrm{mg} / \mathrm{m}^{2}$ were received by 121 (24\%) patients and accounted for 517 (16\%) of all infusions administered during the study period. Overall, 361 out of 509 (71\%) received concomitant therapy, of which the most common were glatiramer acetate (25.3\%), methylprednisolone IV (21.0\%), interferon beta-1a intramuscularly (20.6\%), interferon beta1b (14.9\%), interferon beta-1a subcutaneous (11.8\%), and oral prednisone $(5.7 \%)$. Treatment discontinuation was reported in 486 (95.5\%) patients (Table 2). The most frequently cited reasons for treatment discontinuation were physician decision (28.7\%) and patient's request (25.9\%).

\section{Cardiovascular AEs}

Ten patients experienced CHF during the trial (six during the treatment phase and four during the annual follow-up phase). The median latency of $\mathrm{CHF}$ events from the first dose of Mitoxantrone was 24.2 months (range 9.535.6 months) (Figure 2). Twenty-seven of 509 patients (5.3\%) during the treatment phase and 14 of 250 patients (5.6\%) during the annual follow-up phase experienced LVEF test results that decreased to below 50\%. The median latency of LVEF reductions below 50\% from the first dose of Mitoxantrone during the treatment phase was 29 months (range 13.3-44.6 months) (Figure 2). Twentyfive cardiac-related SAEs were reported among 22 of 509 


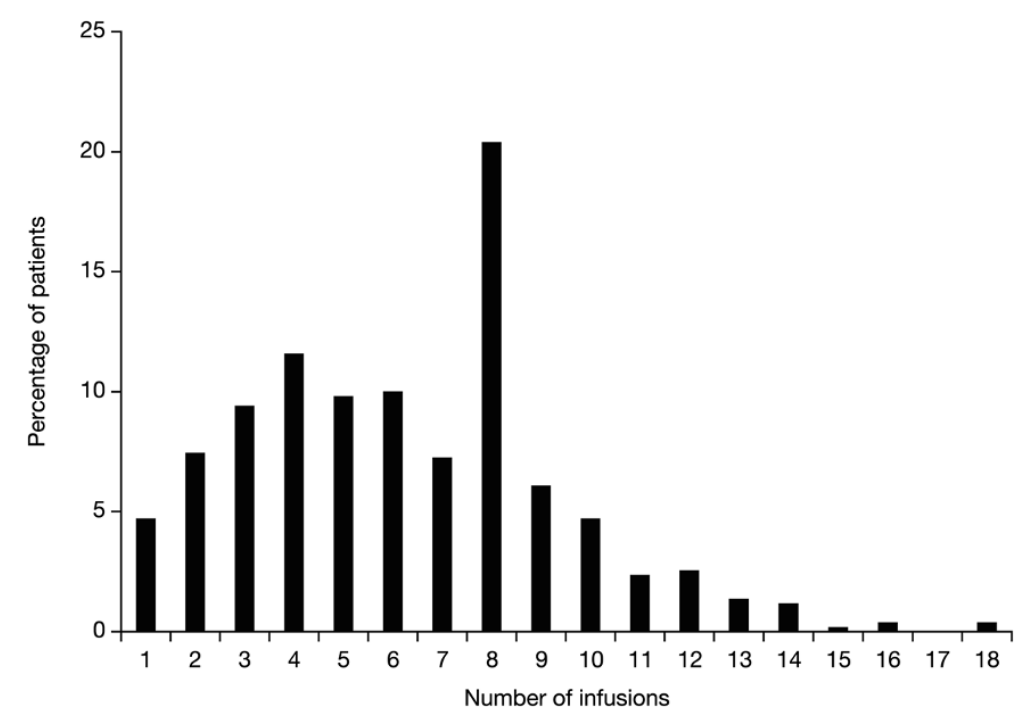

Figure 1 Distribution of the number of infusions of Mitoxantrone*. ${ }^{*}$ Includes only patients who received at least one dose of Mitoxantrone

patients $(4.3 \%)$ during the treatment phase, with the most common being ejection fraction decreased (12 patients, 2.4\%; 12 events) (Table 3). During the annual follow-up phase, five cardiac-related SAEs were reported in four of 250 patients (1.6\%). These events included ejection fraction decreased (two patients, $0.8 \%$; two events), cardiomyopathy (two patients; $0.8 \%$; two events), and tachycardia (one patient, $0.4 \%$; one event) (Table 3).
In response to a Food and Drug Administration request, additional post-hoc analyses of the RENEW study were completed. These analyses were intended to provide valid estimates of the risk for cardiotoxicity outcomes in the RENEW study, and to examine the impact of potential explanatory factors on cardiotoxicity risk among this cohort of MS patients. Results showed that the cumulative dose of Mitoxantrone is the primary risk factor associated with

Table 2 RENEW treatment discontinuations

\begin{tabular}{|c|c|c|c|c|}
\hline & \multirow[t]{3}{*}{ Overall } & \multicolumn{3}{|c|}{ Type of MS } \\
\hline & & Worsening & PRMS & SPMS \\
\hline & & \multicolumn{3}{|l|}{ RRMS } \\
\hline Patients enrolled ${ }^{\mathrm{a}}$ & 509 & 81 & 33 & 395 \\
\hline Discontinued treatment, $\mathrm{n}(\%)$ & $486(95.5)$ & $74(91.4)$ & $32(97.0)$ & $380(96.2)$ \\
\hline Death $^{\mathrm{b}}$ & $4(0.8)$ & $1(1.2)$ & 0 & $3(0.8)$ \\
\hline Other adverse event & $14(2.8)$ & $2(2.5)$ & $2(6.1)$ & $10(2.5)$ \\
\hline Physician decision & $146(28.7)$ & $28(34.6)$ & $6(18.2)$ & $112(28.4)$ \\
\hline Reached maximum cumulative dose $\left(\geq 140 \mathrm{mg} / \mathrm{m}^{2}\right)^{c}$ & $23(4.5)$ & $5(6.2)$ & $1(3.0)$ & $17(4.3)$ \\
\hline Lack of efficacy & $16(3.1)$ & 0 & $2(6.1)$ & $14(3.5)$ \\
\hline Lost to follow-up & $40(7.9)$ & $3(3.7)$ & $2(6.1)$ & $35(8.9)$ \\
\hline LVEF $<50 \%$ & $25(4.9)$ & 0 & $1(3.0)$ & $24(6.1)$ \\
\hline Clinically significant decrease in LVEF or occurrence of $\mathrm{CHF}^{\mathrm{d}}$ & $10(2.0)$ & $2(2.5)$ & $2(6.1)$ & $6(1.5)$ \\
\hline Patient request & $132(25.9)$ & $24(29.6)$ & $11(33.3)$ & $97(24.6)$ \\
\hline Other & $98(19.3)$ & $16(19.8)$ & $6(18.2)$ & $76(19.2)$ \\
\hline Unknown & $1(0.2)$ & 0 & 0 & $1(0.3)$ \\
\hline
\end{tabular}

$\mathrm{CHF}=$ congestive heart failure; $\mathrm{LVEF}=$ left ventricular ejection fraction; $\mathrm{MS}=$ multiple sclerosis; $\mathrm{PRMS}=$ progressive relapsing multiple sclerosis; RENEW=Registry to Evaluate Novantrone Effects in Worsening Multiple Sclerosis; RRMS=relapsing-remitting multiple sclerosis; SPMS=secondary progressive multiple sclerosis. a Patients with validated data who have received at least one dose of Mitoxantrone.

${ }^{\mathrm{b}}$ Eight additional patients died following discontinuation; the reasons for discontinuation of Mitoxantrone treatment were: physician discretion ( $\mathrm{n}=4$ ); patient request $(n=2)$; LVEF $<50 \%(n=1)$; and clinically significant reduction in $\operatorname{LVEF} / C H F(n=1)$.

Includes patients who have reached a cumulative dose of at least $132 \mathrm{mg} / \mathrm{m}^{2}$.

${ }^{d}$ Clinical significance determined by the study site investigator. 


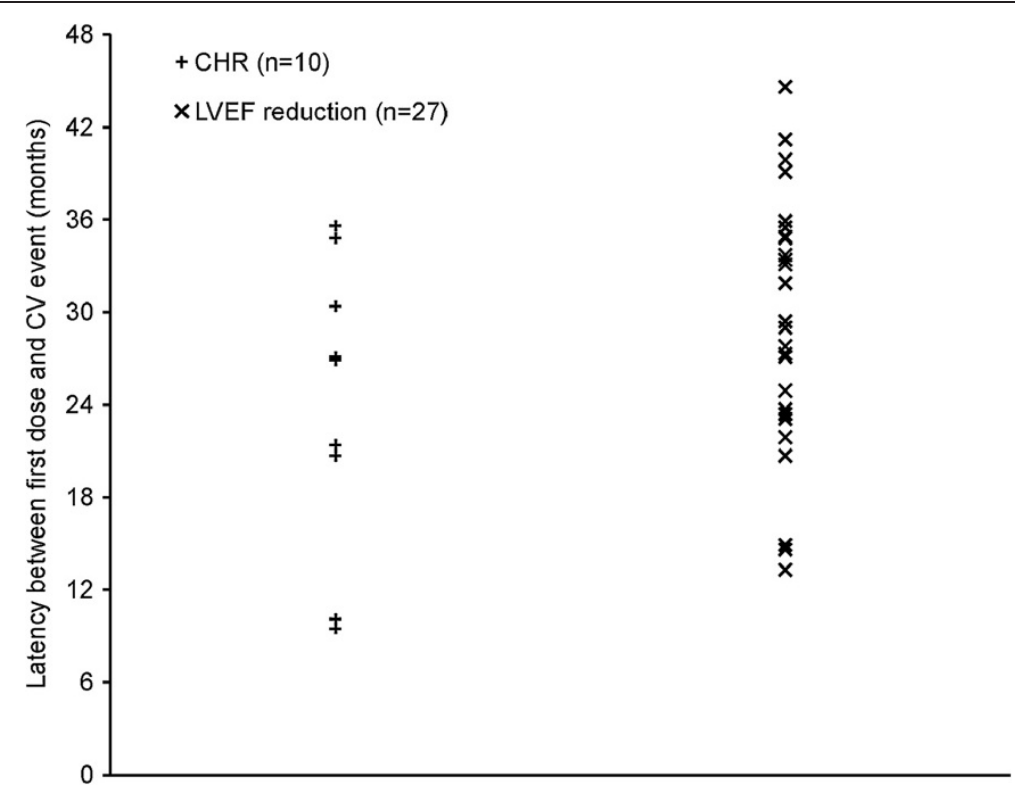

Figure 2 Latency of CHF events and LVEF $<50 \%$ events. CHF=congestive heart failure; CV=cardiovascular; LVEF=left ventricular ejection fraction.

cardiotoxicity (Table 4). The mean cumulative dose was higher in patients with cardiac events $\left(\mathrm{n}=97 ; 93.9 \mathrm{mg} / \mathrm{m}^{2}\right)$ than in those without cardiac events $\left(\mathrm{n}=412 ; 63.7 \mathrm{mg} / \mathrm{m}^{2}\right)$. The dose-dependent, cardiotoxic effect of Mitoxantrone was confirmed to be statistically significant when cumulative dose was analyzed as a dichotomous covariate (Figure 3). Among patients with cardiac events, $74.2 \%$ of patients received doses $>75 \mathrm{mg} / \mathrm{m}^{2}$ compared with $25.8 \%$ of patients who received $\leq 75 \mathrm{mg} / \mathrm{m}^{2}(\mathrm{p}<0.0001)$. Though not statistically significant, there were consistent trends suggesting higher cardiac toxicity in various populations, including: higher age group; SPMS vs relapsing MS; longer disease duration; higher EDSS; use of concomitant immunosuppressants and/or disease-modifying drugs (see Additional file 1). Lastly, use of Mitoxantrone and previous or concomitant use of oral Methotrexate was significantly associated with cardiotoxicity risk and there was a trend toward significance when oral Methotrexate was used after study entry (Figure 4).

\section{Hematologic effects}

Leukemia was reported in three patients, resulting in an incidence rate of $0.6 \%$. Among these cases, two occurred during the annual follow-up phase of the study. In case 1 , the patient was diagnosed with acute myelogenous leukemia (AML), M4 type in 2004, approximately 30 months following the first dose of Mitoxantrone (total cumulative dose was $73.5 \mathrm{mg} / \mathrm{m}^{2}$ ). The patient received chemotherapy and achieved remission in November 2005. As of January 2008,

Table 3 Summary of cardiac-related SAEs

\begin{tabular}{lccc}
\hline SAE, $\mathbf{n}(\%)$ & $\begin{array}{c}\text { Overall } \\
(\mathbf{N}=\mathbf{5 0 9})\end{array}$ & $\begin{array}{c}\text { Treatment phase } \\
\mathbf{( n = 5 0 9 )}\end{array}$ & $\begin{array}{c}\text { Annual follow-up } \\
\text { phase } \mathbf{( n = 2 5 0 )}\end{array}$ \\
\hline Any cardiac event & $25^{\text {a }}(4.9)$ & $22(4.3)$ & $4(1.6)$ \\
Reduced LVEF & $14(2.8)$ & $12(2.4)$ & $2(0.8)$ \\
Myocardial infarction & $4(0.8)$ & $4(0.8)$ & 0 \\
Cardiomyopathy & $5(1.0)$ & $3(0.6)$ & $2(0.8)$ \\
Congestive heart failure & $2(0.4)$ & $2(0.4)$ & 0 \\
Cardiorespiratory arrest & $1(0.2)$ & $1(0.2)$ & 0 \\
Mitral valve incompetence & $1(0.2)$ & $1(0.2)$ & 0 \\
Tachycardia & $2(0.4)$ & $1(0.2)$ & $1(0.4)$ \\
Ventricular hypokinesia & $1(0.2)$ & $1(0.2)$ & 0 \\
\hline
\end{tabular}


Table 4 Association between cardiotoxicity risk and cumulative dose

\begin{tabular}{|c|c|c|c|c|}
\hline $\begin{array}{l}\text { Cumulative dose } \\
\text { category, } \mathrm{n}(\%)\end{array}$ & $\begin{array}{l}\text { Overall } \\
(N=509)\end{array}$ & $\begin{array}{l}\text { Patients with } \\
\text { cardiac events } \\
\quad(n=97)\end{array}$ & $\begin{array}{l}\text { Patients without } \\
\text { cardiac events } \\
(n=412)\end{array}$ & value $^{p}$ \\
\hline$>0$ and $\leq 35 \mathrm{mg} / \mathrm{m}^{2}$ & $82(16.1)$ & $6(6.2)$ & $76(18.4)$ & REF \\
\hline$>35$ and $\leq 75 \mathrm{mg} / \mathrm{m}^{2}$ & $204(40.1)$ & 19 (19.6) & $185(44.9)$ & $>0.05$ \\
\hline$>75$ and $\leq 105 \mathrm{mg} / \mathrm{m}^{2}$ & 149 (29.3) & $33(34.0)$ & $116(28.2)$ & $<0.01$ \\
\hline$>105 \mathrm{mg} / \mathrm{m}^{2}$ & $74(14.5)$ & $39(40.2)$ & $35(8.5)$ & $<0.0001$ \\
\hline
\end{tabular}

${ }^{\mathrm{a}}$ From Poisson and logistic regression models; pairwise comparisons of cumulative dose categories are presented with lowest dose category as reference. $\mathrm{REF}=$ reference value.

the patient was stable with no recurrence. In case 2, the patient was diagnosed with chronic phase chronic myeloid leukemia (CML) in 2006, approximately 63 months following the first dose of Mitoxantrone (total cumulative dose was $107.3 \mathrm{mg} / \mathrm{m}^{2}$ ). In June 2006 (exact date unknown), the patient began therapy with imatinib. On 28 June 2006, the patient's white blood cell count fell from 30,000 to 18,900 and the event was not resolved. No additional information regarding the outcome of case 2 is available at this time. Case 3 involved a patient who developed acute promyelocytic leukemia (APL). The total cumulative dose of Mitoxantrone was $97.1 \mathrm{mg} / \mathrm{m}^{2}$ (first dose on 29 December 2000 and last dose on 3 October 2003). Details regarding the date of APL diagnosis and outcome were not included in the initial report. Three requests for information were made to the trial site to obtain details surrounding the diagnosis of APL (including pathology reports) and subsequent treatment and outcome, but no further information on the patient's leukemia was obtainable.

\section{Amenorrhea}

At baseline, 128 women reported regular menses. During the treatment phase of the study, 28 (22\%) women developed persistent amenorrhea having received a mean $\mathrm{cu}-$ mulative dose of $52.1 \mathrm{mg} / \mathrm{m}^{2}$, and five (4\%) women developed transient amenorrhea having received a mean cumulative dose of $70.5 \mathrm{mg} / \mathrm{m}^{2}$. During the annual followup phase, 73 women reported regular menses at baseline; of these women, four (5\%) developed persistent amenorrhea while one (1\%) developed transient amenorrhea.

Forty-nine women reported irregular menses at baseline; of these women, 25 (51\%) developed persistent amenorrhea having received a mean cumulative dose of $38.2 \mathrm{mg} /$ $\mathrm{m}^{2}$ during the treatment phase of the study, and one (2\%) developed transient amenorrhea having received a cumulative dose of $59 \mathrm{mg} / \mathrm{m}^{2}$. During the annual follow-up phase, no patients with irregular menses at baseline developed persistent amenorrhea while only one of 26 women (4\%) developed transient amenorrhea. During the treatment phase of the study, resumption of menses was reported by

- Patients without cardiac events ( $n=412)$ aPatients with cardiac events $(n=97)$

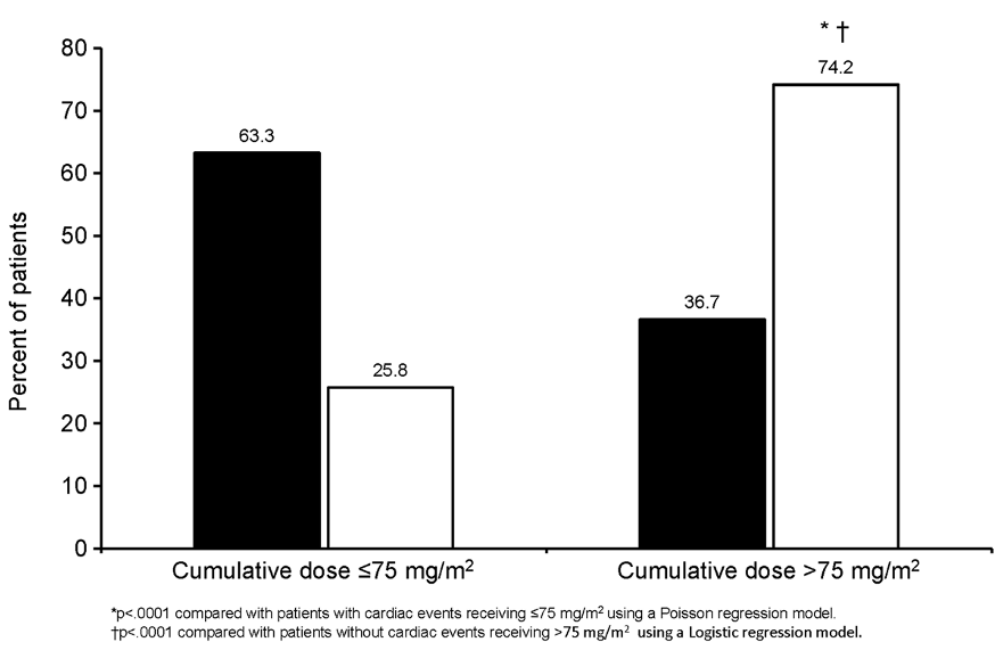

Figure 3 Association between cardiotoxicity risk and cumulative dose. Cardiac events includes patients with reported cardiac SAES, with signs or symptoms of CHF requiring hospitalization or other therapy, with an LVEF decrease to $50 \%$ of baseline, or with a clinically significant drop in LVEF as indicated by a 10\% decrease from baseline. CHF=congestive heart failure; LVEF=left ventricular ejection fraction; SAE=serious adverse event. 


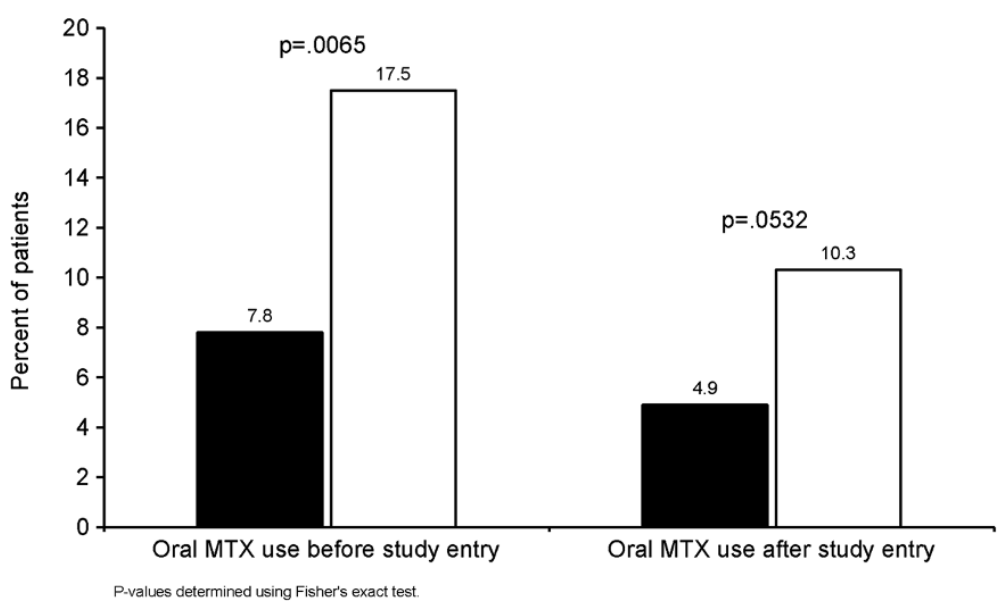

Figure 4 Risk of cardiotoxicity with prior and/or concomitant Methotrexate therapy. Cardiac events includes patients with reported cardiac SAES, with signs or symptoms of CHF requiring hospitalization or other therapy, with an LVEF decrease to 50\% of baseline, or with a clinically significant drop in LVEF as indicated by a 10\% decrease from baseline. CHF=congestive heart failure; LVEF=left ventricular ejection fraction; MTX=Methotrexate; SAE=serious adverse event.

three women $(1.8 \%)$ who received a cumulative dose of $23 \mathrm{mg} / \mathrm{m}^{2}$ and had reported an absence of menses at baseline; no patients with absent menses at baseline resumed menses during the observational phase.

\section{AEs and deaths}

During the treatment phase, a total of 143 SAEs were reported in 88 patients (see Table 5 and Additional file 2). The most commonly reported SAE during the treatment phase was decreased ejection fraction (12 patients, 2.4\%; 12 events, 11 of which were considered treatment related). During the annual follow-up phase of the study, 23 patients experienced 39 SAEs (see Table 6 and Additional file 2). The most commonly reported SAE during the annual follow-up phase was urinary tract infection (UTI) (three patients, $1.2 \%$; four events).

A total of 60 cases of serious infection were reported ( $\mathrm{n}=41$ ) during the study (see Additional file 3). During the treatment phase, 38 (7.5\%) patients had 47 infectious SAEs, with the most common being UTI (11 patients, $2.2 \%$; 13 events). During the annual follow-up phase, eight (3.2\%) patients had 13 serious infectious events, with the most common being UTI (three patients, $1.2 \%$; four events).

Twelve deaths were reported during the study (Table 7). Eight of the 12 deaths occurred during the treatment phase. Median EDSS score was 7 (range 4-9); median cumulative dose was $81.9 \mathrm{mg} / \mathrm{m}^{2}$ (range $11.1-119.4 \mathrm{mg} / \mathrm{m}^{2}$ ). Events accounting for at least two deaths included: infection ( $\mathrm{n}=3$; pneumonia, acute meningitis, and septic shock); cardiac-related SAEs $(\mathrm{n}=2)$, and pulmonary embolism $(n=2)$.

\section{Discussion}

The cardiotoxic risk associated with Mitoxantrone in patients with MS is well-documented [6-15]. In 2010, the Therapeutics and Technology Assessment (TTA) Subcommittee of the American Academy of Neurology reviewed all articles and abstracts published before July 2009 containing 'Mitoxantrone' and 'multiple sclerosis' [25]. Investigators identified and consolidated 11 class III evidence studies to analyze cardiotoxicity. From this analysis $(n=716)$, decreased LVEF was estimated to be approximately $12 \%$ while the risk of $\mathrm{CHF}$ was estimated to be approximately $0.4 \%$; the number needed to harm $(\mathrm{NNH})$ for left ventricular dysfunction was eight. The authors cautioned, however, that these estimates are a general approximation given that dosing regimens and cardiac testing varied among the different treatment centers. More recently, Le Page and colleagues published final results from a 5-year prospective study in a French cohort of 802 MS patients [33]. The final mean cumulative dose of Mitoxantrone in this study was $78 \mathrm{mg} / \mathrm{m}^{2}$, with $18.5 \%$ of patients receiving more than $100 \mathrm{mg} / \mathrm{m}^{2}$; the mean follow-up was 6.7 years. There was one case of acute CHF out of the 802 total patients (0.1\%). Of 794 patients who received LVEF assessment testing, 39 (4.9\%) experienced an asymptomatic decrease of LVEF $<50 \%$. Decreased LVEF $<50 \%$ was reversible in 27 (69.2\%) patients, persistent in $11(28.2 \%)$ patients, and only observed on the last scan in one patient $(2.6 \%)$ remaining clinically symptomatic. Analysis of risk factors did not reveal any factor predictive of the occurrence of a LVEF decrease.

In the RENEW trial, the mean cumulative dose of Mitoxantrone was $69.8 \mathrm{mg} / \mathrm{m}^{2}$ and patients received treatment for an average of 1.5 years. During the treatment 
Table 5 Treatment-related SAEs during RENEW treatment phase

\begin{tabular}{|c|c|c|c|}
\hline \multirow[t]{3}{*}{ SAE } & \multirow{2}{*}{\multicolumn{3}{|c|}{$\begin{array}{c}\text { Treatment phase }(n=509) \\
\text { Number of treatment-related events }\end{array}$}} \\
\hline & & & \\
\hline & Possible & Probable & Total \\
\hline Decreased ejection fraction & 1 & 10 & 11 \\
\hline Urinary tract infection & 1 & 3 & 4 \\
\hline Cardiomyopathy & 0 & 3 & 3 \\
\hline Febrile neutropenia & 1 & 2 & 3 \\
\hline Leukopenia & 0 & 3 & 3 \\
\hline Pneumonia & 0 & 3 & 3 \\
\hline Congestive heart failure & 0 & 2 & 2 \\
\hline Cellulitis gangrenous & 0 & 1 & 1 \\
\hline Herpes zoster & 0 & 1 & 1 \\
\hline Upper respiratory tract infection & 0 & 1 & 1 \\
\hline Urosepsis & 0 & 1 & 1 \\
\hline Ventricular hypokinesia & 0 & 1 & 1 \\
\hline Myocardial infarction & 2 & 0 & 2 \\
\hline Nausea & 2 & 0 & 2 \\
\hline Sepsis & 2 & 0 & 2 \\
\hline Septic shock & 2 & 0 & 2 \\
\hline Vomiting & 2 & 0 & 2 \\
\hline Abortion incomplete & 1 & 0 & 1 \\
\hline Cellulitis & 1 & 0 & 1 \\
\hline Deep vein thrombosis & 1 & 0 & 1 \\
\hline Dizziness & 1 & 0 & 1 \\
\hline Fungal skin infection & 1 & 0 & 1 \\
\hline Hydronephrosis & 1 & 0 & 1 \\
\hline Localized infection & 1 & 0 & 1 \\
\hline Lung infection & 1 & 0 & 1 \\
\hline Meningitis & 1 & 0 & 1 \\
\hline Pituitary tumor & 1 & 0 & 1 \\
\hline Pulmonary embolism & 1 & 0 & 1 \\
\hline Varicella & 1 & 0 & 1 \\
\hline
\end{tabular}

$\mathrm{SAE}=$ serious adverse event; RENEW=Registry to Evaluate Novantrone Effects in Worsening Multiple Sclerosis.

$(\mathrm{N}=509)$ and follow-up $(\mathrm{n}=250)$ phases, LVEF $<50 \%$ occurred in $5.3 \%$ and $5.6 \%$, respectively; CHF was observed in $10(2 \%)$ patients overall. The decreased LVEF rates reported here are comparable to those reported in the French cohort and below the estimate reported by the TTA Subcommittee. Conversely, the rate of CHF in RENEW appears to be significantly higher (at least 5 -fold) compared with either TTA Subcommittee estimates or the French cohort. It should be noted, however, that confirmation of CHF was not required in patients who experienced signs or symptoms of CHF in the RENEW study.
Table 6 Treatment-related SAEs during RENEW annual follow-up phase

\begin{tabular}{lccc}
\hline SAE & \multicolumn{3}{c}{$\begin{array}{c}\text { Annual follow-up phase }(\mathbf{n}=\mathbf{2 5 0}) \\
\text { Number of treatment-related events }\end{array}$} \\
\cline { 2 - 4 } & Possible & Probable & Total \\
\hline Decreased ejection fraction & 0 & 2 & 2 \\
Acute myeloid leukemia & 0 & 1 & 1 \\
Pneumonia & 0 & 1 & 1 \\
Anorexia & 1 & 0 & 1 \\
Cardiomyopathy & 1 & 0 & 1 \\
Tachycardia & 1 & 0 & 1 \\
Chronic myeloid leukemia & 1 & 0 & 1 \\
Endometrial cancer & 1 & 0 & 1 \\
Carotid artery occlusion & 1 & 0 & 1 \\
Cerebrovascular accident & 1 & 0 & 1 \\
Dyspnea & 1 & 0 & 1 \\
\hline SAE & 1 & & 1 \\
\hline
\end{tabular}

SAE=serious adverse event; RENEW=Registry to Evaluate Novantrone Effects in Worsening Multiple Sclerosis.

Post-hoc analyses of risk factors revealed that the cumulative dose of Mitoxantrone is the primary risk factor associated with cardiotoxicity in RENEW. There were also consistent trends suggesting higher cardiac toxicity in various sub-populations of patients, including: higher age group, SPMS vs relapsing MS, longer disease duration, higher EDSS, use of concomitant immunosuppressants and/or disease-modifying drugs. The independent contribution of any one of these individual demographic and disease characteristics to the risk of cardiotoxicity needs to be interpreted with caution since they may be interrelated and therefore coexist in the same patient (e. g., an older subject will have had MS for a longer period of time and may have accumulated a higher EDSS score, leading to attempts by clinicians to add other drugs (i.e., immunosuppressants and/or disease-modifying drugs)). The independent contribution of any of these factors to a higher predisposition to risk of cardiac toxicity with Mitoxantrone is unknown. Results also suggested that previous or concomitant treatment with oral Methotrexate may also increase the risk of cardiotoxicity. The cardiovascular risks associated with Methotrexate, however, have yet to be established in patients with MS. The majority of studies evaluating the impact of Methotrexate on cardiovascular events have focused on patients with rheumatoid arthritis (RA), a systemic inflammatory disease associated with an increased risk for morbidity and mortality from cardiovascular disease [34]. Analysis in prospective [35], observational [36], and retrospective [37] studies have suggested that Methotrexate is cardioprotective in RA patients. Conversely, a longitudinal cohort study analyzing data from 10,156 patients enrolled in the Consortium of Rheumatology Researchers of North America Rheumatoid 
Table 7 Deaths during the RENEW study

\begin{tabular}{|c|c|c|c|c|c|c|c|}
\hline Count & $\begin{array}{l}\text { Age (years)/ } \\
\text { gender }\end{array}$ & $\begin{array}{l}\text { Form } \\
\text { of MS }\end{array}$ & $\begin{array}{l}\text { Baseline } \\
\text { EDSS }\end{array}$ & Cause(s) & Study phase & $\begin{array}{l}\text { Treatment } \\
\text { related? }\end{array}$ & $\begin{array}{l}\text { Cumulative } \\
\text { dose } \mathrm{mg} / \mathrm{m}^{2}\end{array}$ \\
\hline 1 & $51 / F$ & SPMS & 7 & Pneumonia & Treatment & No & 91.3 \\
\hline 2 & $43 / F$ & SPMS & 6 & $\begin{array}{l}\text { Decreased ejection fraction, } \\
\text { cardiomyopathy, congestive heart } \\
\text { failure }\end{array}$ & Treatment & Probable & 96.8 \\
\hline 3 & $50 / F$ & SPMS & 8.5 & Pulmonary embolism & Treatment & No & 12.2 \\
\hline 4 & $57 / M$ & SPMS & 7 & Road traffic accident & Annual follow-up & No & 99.7 \\
\hline 5 & $57 / M$ & SPMS & 6 & Prostate cancer & Treatment & No & Unknown \\
\hline 6 & $49 / M$ & SPMS & 6.5 & $\begin{array}{l}\text { Cerebrovascular accident, carotid } \\
\text { artery occlusion }\end{array}$ & Annual follow-up & Possible & 119.4 \\
\hline 7 & $57 / M$ & PRMS & 7 & Pulmonary edema & Annual follow-up & Unknown & 109.5 \\
\hline 8 & $55 / F$ & SPMS & 6.5 & Pulmonary embolism & Annual follow-up & No & 67.7 \\
\hline 9 & $51 / F$ & RRMS & 4 & Acute meningitis & Treatment & Possible & 11.9 \\
\hline 10 & $68 / M$ & SPMS & 7.5 & Respiratory failure & Treatment & No & 11.1 \\
\hline 11 & $37 / F$ & SPMS & 9 & Cardiopulmonary arrest & Treatment & No & 18.4 \\
\hline 12 & $44 / F$ & SPMS & 7 & Septic shock & Treatment & Possible & 81.9 \\
\hline
\end{tabular}

EDSS=Expanded Disability Status Scale; $\mathrm{F}=$ female; $\mathrm{M}=$ male; $\mathrm{MS}=$ multiple sclerosis; PRMS=progressive relapsing multiple sclerosis; RENEW=Registry to Evaluate Novantrone Effects in Worsening Multiple Sclerosis; SPMS=secondary progressive multiple sclerosis.

Arthritis registry reported that Methotrexate was not associated with a reduced risk of the primary composite cardiovascular endpoint of incident non-fatal myocardial infarction, non-fatal stroke or transient ischemic attack, and cardiovascular-related death [38]. Controversy exists on whether chronic MS is associated with cardiovascular disease, with studies suggesting an association [39] and others rejecting it $[40,41]$. The association between Methotrexate and cardiotoxicity observed in RENEW remains speculative since analysis was post-hoc rather than prespecified. Furthermore, analysis with a larger cohort of patients is also required to confirm the role of age and Methotrexate therapy as predictive factors of cardiotoxicity.

Reports from Spanish cohorts have raised concerns about the increased risk of leukemia in MS patients treated with Mitoxantrone $[17,28]$. In the report by Pascual and colleagues [28], investigators reported results from two separate Spanish cohorts. In the first cohort treated with Mitoxantrone [17,28], there were four cases of leukemia among 142 patients with RRMS and SPMS. The four patients received total Mitoxantrone doses of 30,60, 70, and $100 \mathrm{mg} / \mathrm{m}^{2}$. The cumulative incidence of leukemia was $2.82 \%$ (95\% CI, 1.2-4.4) over a median follow-up time of 40 months since the start of treatment. In the second cohort containing 88 patients with MS [28], there were two cases of leukemia in patients receiving $137 \mathrm{mg} / \mathrm{m}^{2}$ and $159 \mathrm{mg} / \mathrm{m}^{2}$ of Mitoxantrone, respectively. The cumulative incidence of treatment-related leukemia in this cohort was 2.27\% (95\% CI, 1.1-3.4).

In contrast, analysis of leukemia among the French cohort identified two cases of Mitoxantrone-related leukemia to yield an incidence of $0.25 \%$. The total cumulative dose of Mitoxantrone was $70 \mathrm{mg} / \mathrm{m}^{2}$ in each case [33]. In addition, retrospective analysis of data from 40 Italian MS centers identified 30 cases of AML among 3,220 patients treated with Mitoxantrone, yielding an incidence of $0.93 \%$. Furthermore, the authors reported that MS patients presenting with $\mathrm{AML}$ received a significantly higher dose of Mitoxantrone compared with their non-AML counterparts (78.3 vs $64.7 \mathrm{mg} / \mathrm{m}^{2}$, respectively; $\mathrm{p}=0.028$ ) [26].

In the RENEW study, there were three reports of Mitoxantrone-related leukemia (AML and CML) among the 509 patients (incidence of $0.6 \%$ ). The total cumulative dose was $73.5 \mathrm{mg} / \mathrm{m}^{2}, 107.3 \mathrm{mg} / \mathrm{m}^{2}$, and $97.1 \mathrm{mg} / \mathrm{m}^{2}$ for each case. These results are consistent with results from the French and Italian cohort studies. RENEW results are also consistent with a TTA Subcommittee analysis of treatment-related leukemia among 4,076 patients combined from 32 class III or IV evidence studies [25]. According to TTA estimates, the incidence of treatment-related leukemia in patients with MS is approximately $0.81 \%$, with a $\mathrm{NNH}$ of 123. Again, the authors caution that this is a general approximation given the variability in time of follow-up among the different studies, especially case reports.

The disparity in incidence rates between RENEW/ French cohort and the Spanish cohort is not completely understood. It is worth noting, however, that the mean cumulative dose was $87.7 \mathrm{mg} / \mathrm{m}^{2}$ when the 10 patients from the respective cohorts are combined. Given the dosedependent data reported by the Italian group [26], it is reasonable to speculate that the 10 patients from the combined cohorts were at higher risk for developing 
treatment-related leukemia by virtue of their cumulative dose. Genetic risk cannot be ruled out either.

The French cohort evaluated the reproductive safety profile of Mitoxantrone in 317 women with MS starting treatment at 45 years of age or younger [33]. Transient amenorrhea was observed in $27 \%$ of women while persistent amenorrhea was observed in $17.3 \%$ of women. No persistent amenorrhea, however, was observed in women treated before the age of 25 . The likelihood of experiencing persistent amenorrhea increased with age in this cohort. In the RENEW trial, the incidence of transient amenorrhea (4\% during the treatment phase and $1 \%$ during follow-up) was lower compared with the French cohort. The incidence of persistent amenorrhea was consistent between studies (22\% during the treatment phase and 5\% during follow-up in RENEW). In the RENEW cohort, women who at baseline reported irregular menses had a higher incidence $(51 \%)$ of persistent amenorrhea compared to women who reported regular menses (22\%), despite the fact that the mean cumulative dose of Mitoxantrone was higher in the latter group. These results indicate that women with menstrual irregularity are at higher risk of developing persistent amenorrhea while taking Mitoxantrone.

\section{Conclusion}

RENEW provides additional data on the long-term safety of Mitoxantrone in patients with worsening MS. There are limitations that must be considered when evaluating this data. First, RENEW data are registry-based, and not from a controlled trial. As a result, more than half of the patients were lost during the 5-year planned follow-up. Patient drop out, therefore, may lead to underestimation of the incidence of cardiovascular events, leukemia, and SAEs reported here. To ascertain whether there are more cases of cardiovascular events or leukemia, a second RENEW Study has been initiated to contact patients who originally left RENEW for reasons other than death or lost to follow-up. Another factor that may lead to underestimation of Mitoxantrone-related SAEs includes the protocol for evaluating SAE by relationship to study drug. In RENEW, SAE by relationship to study drug was determined by the local study investigator rather than an independent review board. Lastly, there is also complexity in data interpretation due to variability in physician behaviour/use of Mitoxantrone (on-label vs off-label) and variability in severity of patient disease when first treated with Mitoxantrone.

Taking study limitations into consideration, the data reported here demonstrate that, consistent with previous reports, Mitoxantrone therapy in MS patients is associated with significant side effects, and that Mitoxantrone cumulative dose exposure is clearly associated with cardiac toxicity. Use of Mitoxantrone in worsening RRMS, transitional forms, and in patients no longer responding to first-line therapies should be cautiously considered, and prescribing physicians should: 1) stay on-label, 2) use the lowest possible cumulative dose that achieves the desired clinical effect and 3) vigilantly monitor patients for clinical, cardiac, and neoplastic complications before every dose of Mitoxantrone and annually following treatment.

\section{Additional files}

Additional file 1: Potential cardiac risk explanatory factors: demographic, disease history, dosing (population: all treated subjects).

Additional file 2: Serious adverse events reported during the treatment and annual follow-up phases of RENEW.

Additional file 3: Serious infection events by relationship to Mitoxantrone during the treatment and follow-up phases of RENEW.

\section{Competing interests}

VMR declared that there is no conflict of interest. DRJ has received honoraria for speaking and consulting with Bayer, Biogen Idec, Teva, EMD Serono, Pfizer, Novartis, Genzyme, Roche, and Acorda. BWG has participated in speaker's bureaus and served as a consultant for Biogen Idec, Teva Neuroscience, EMD Serono, Pfizer, Novartis, Genzyme, and Acorda. Excluding Genzyme, BWG has also received grant/research support from the aforementioned companies as well as ITN, Questcor, and Shire. No other industry financial relationships exist. DB was an employee at EMD Serono during the development of this manuscript. DB is currently an employee at BDM Consulting, Inc and declares no other industry financial relationships. FD is an employee of EMD Serono, receiving salary and employment benefits from the company.

\section{Authors' contributions}

VMR, DRJ, BWG and FD participated in the analysis and interpretation of data. DB contributed to the acquisition of data and performed the statistical analyses. All authors read and approved the final manuscript.

\section{Acknowledgments}

The authors wish to thank Randy Bennett and Daryl Dawson of EMD Serono, Inc for their contributions to this manuscript. Molly VanZant and Erin Hopkins of REGISTRAT-MAPI planned and conducted the statistical analysis. Medical writing/editorial support was provided by Caroline Hoang, PhD of ACUMED (New York, NY), and was funded by EMD Serono, Inc.

This study was sponsored by EMD Serono, Inc, a subsidiary of Merck KGaA, Darmstadt, Germany.

\section{Author details}

${ }^{1}$ Baylor College of Medicine, Houston, TX, USA. ${ }^{2}$ Cornerstone Health Care, Advance, NC, USA. ${ }^{3}$ Jacobs Neurological Institute, State University of New York-University of Buffalo, Buffalo, NY, USA. ${ }^{4}$ EMD Serono Inc, Rockland, MA, USA.

Received: 20 November 2012 Accepted: 1 July 2013

Published: 11 July 2013

\section{References}

1. Levine S, Saltzman A: Regional suppression, therapy after onset and prevention of relapses in experimental allergic encephalomyelitis by Mitoxantrone. J Neuroimmunol 1986, 13:175-181.

2. Lublin FD, Lavasa M, Viti C, Knobler RL: Suppression of acute and relapsing experimental allergic encephalomyelitis with Mitoxantrone. Clin Immunol Immunopathol 1987, 45:122-128.

3. Watson CM, Davison AN, Baker D, O'Neill JK, Turk JL: Suppression of demyelination by Mitoxantrone. Int J Immunopharmacol 1991, 13:923-930.

4. Edan G, Miller D, Clanet M, Confavreux C, Lyon-Caen O, Lubetzki C, Brochet B, Berry I, Rolland Y, Froment JC, Cabanis E, Iba-Zizen MT, Gandon JM, Lai HM, Moseley I, Sabouraud O: Therapeutic effect of Mitoxantrone combined with methylprednisolone in multiple sclerosis: a randomised 
multicentre study of active disease using MRI and clinical criteria. J Neurol Neurosurg Psychiatry 1997, 62:112-118.

5. Hartung HP, Gonsette R, König N, Kwiecinski H, Guseo A, Morrissey SP, Krapf $H$, Zwingers T: Mitoxantrone in Multiple Sclerosis Study Group (MIMS): Mitoxantrone in progressive multiple sclerosis: a placebo-controlled, double-blind, randomised, multicentre trial. Lancet 2002, 360:2018-2025.

6. Avasarala JR, Cross AH, Clifford DB, Singer BA, Siegel BA, Abbey EE: Rapid onset Mitoxantrone-induced cardiotoxicity in secondary progressive multiple sclerosis. Mult Scler 2003, 9:59-62.

7. De-Castro CS, Cartoni D, Millefiorini E, Funaro S, Gasperini C, Morino S, Tallarico D, Beni S: Non-invasive assessment of mitoxantrone cardiotoxicity in relapsing remitting multiple sclerosis. J Clin Pharmacol 1995, 35:627-632.

8. Ghalie RG, Edan G, Laurent M, Mauch E, Eisenman S, Hartung HP, Gonsette RE, Butine MD, Goodkin DE: Cardiac adverse effects associated with Mitoxantrone (Novantrone) therapy in patients with MS. Neurology 2002, 59:909-913.

9. Hamzehloo A, Etemadifar M: Mitoxantrone-induced cardiotoxicity in patients with multiple sclerosis. Arch Iran Med 2006, 9:111-114.

10. Paul F, Dörr J, Würfel J, Vogel HP, Zipp F: Early Mitoxantrone-induced cardiotoxicity in secondary progressive multiple sclerosis. $J$ Neurol Neurosurg Psychiatry 2007, 78:198-200.

11. Zingler VC, Nabauer M, Jahn K, Gross A, Hohlfeld R, Brandt T, Strupp M: Assessment of potential cardiotoxic side effects of Mitoxantrone in patients with multiple sclerosis. Eur Neurol 2005, 54:28-33.

12. Goffette $S$, van-Pesch V, Vanoverschelde JL, Morandini E, Sindic CJ: Severe delayed heart failure in three multiple sclerosis patients previously treated with Mitoxantrone. J Neurol 2005, 252:1217-1222.

13. Khatri BO, Wroblewski M, Kramer CJ, Dukic M, Poplar A, Anderson AJ: Mitoxantrone in worsening secondary progressive multiple sclerosis: a prospective, open-label study. CurrTher Res 2006, 67:55-65.

14. Ostberg A, Pittas F, V B: Use of low-dose Mitoxantrone to treat aggressive multiple sclerosis: a single-centre open-label study using patient selfassessment and clinical measures of multiple sclerosis status. Intern Med J 2005, 35:382-387.

15. Buttinelli C, Clemenzi A, Borriello G, Denaro F, Pozzilli C, Fieschi C Mitoxantrone treatment in multiple sclerosis: a 5-year clinical and MRI follow-up. Eur J Neurol 2007, 14:1281-1287.

16. Arruda WO, Montú MB, de-Oliveira MS, Ramina R: Acute myeloid leukaemia induced by Mitoxantrone: case report. Arq Neuropsiquiatr 2005, 63:327-329.

17. Bosca I, Pascual AM, Casanova B, Coret F, Sanz MA: Four new cases of therapy-related acute promyelocytic leukemia after Mitoxantrone. Neurology 2008, 71:457-458.

18. Brassat D, Recher C, Waubant E, Le-Page E, Rigal-Huguet F, Laurent G, Edan G, Clanet M: Therapy-related acute myeloblastic leukemia after Mitoxantrone treatment in a patient with MS. Neurology 2002, 59:954-955.

19. Cattaneo C, Almici C, Borlenghi E, Motta M, Rossi G: A case of acute promyelocytic leukaemia following Mitoxantrone treatment of multiple sclerosis. Leukemia 2003, 17:985-986.

20. Delisse B, de-Seze J, Mackowiak A, N'Kendjuo JB, Verier A, Derepeer O, Boisselier C, Devos P, Hautecoeur P, Vermersch P, G-SEP: Therapy related acute myeloblastic leukaemia after Mitoxantrone treatment in a patient with multiple sclerosis. Mult Scler 2004, 10:92.

21. Ellis R, Boggild M: Therapy-related acute leukaemia with Mitoxantrone: what is the risk and can we minimise it? Mult Scler 2009, 15:505-508.

22. Ghalie RG, Mauch E, Edan G, Hartung HP, Gonsette RE, Eisenmann S, Le-Page E, Butine MD, De-Goodkin DE: A study of therapy-related acute leukaemia after Mitoxantrone therapy for multiple sclerosis. Mult Scler 2002, 8:441-445

23. Heesen C, Bruegmann M, Gbdamosi J, Koch E, Mönch A, Buhmann C: Therapy-related acute myelogenous leukaemia (t-AML) in a patient with multiple sclerosis treated with Mitoxantrone. Mult Scler 2003, 9:213-214.

24. Ledda A, Caocci G, Spinicci G, Cocco E, Mamusa E, La Nasa G: Two new cases of acute promyelocytic leukemia following Mitoxantrone treatment in patients with multiple sclerosis. Leukemia 2006, 20:2217-2218.

25. Marriott JJ, Miyasaki JM, Gronseth G, O'Connor PW, Therapeutics and Technology Assessment Subcommittee of the American Academy of Neurology: Evidence Report: The efficacy and safety of Mitoxantrone (Novantrone) in the treatment of multiple sclerosis: Report of the Therapeutics and Technology Assessment Subcommittee of the American Academy of Neurology. Neurology 2010, 74:1463-1470.
26. Martinelli V, Cocco E, Capra R, Salemi G, Gallo P, Capobianco M, Pesci I, Ghezzi A, Pozzilli C, Lugaresi A, Bellantonio P, Amato MP, Grimaldi LM, Tojano M, Mancardi GL, Bergamaschi R, Gasperini C, Rodegher M, Straffi L, Ponzio M, Comi G, Italian Mitoxantrone Group: Acute myeloid leukemia in Italian patients with multiple sclerosis treated with Mitoxantrone. Neurology 2011, 77:1887-1895.

27. Novoselac AV, Reddy S, Sanmugarajah J: Acute promyelocytic leukemia in a patient with multiple sclerosis following treatment with Mitoxantrone. Leukemia 2004, 18:1561-1562.

28. Pascual AM, Téllez N, Boscá I, Mallada J, Belenguer A, Abellán I, Sempere AP, Fernández P, Magraner MJ, Coret F, Sanz MA, Montalbán X, Casanova B: Revision of the risk of secondary leukaemia after Mitoxantrone in multiple sclerosis populations is required. Mult Scler 2009, 15:1303-1310.

29. Tanasescu R, Debouverie M, Pittion S, Anxionnat R, Vespignani H: Acute myeloid leukaemia induced by Mitoxantrone in a multiple sclerosis patient. J Neurol 2004, 251:762-763.

30. Vicari AM, Ciceri F, Folli F, Lanzi R, Colombo B, Comi G, Camba L: Acute promyelocytic leukemia following Mitoxantrone as single agent for the treatment of multiple sclerosis. Leukemia 1998, 12:441-442.

31. Voltz R, Starck M, Zingler V, Strupp M, Kolb HJ: Mitoxantrone therapy in multiple sclerosis and acute leukaemia: a case report out of 644 treated patients. Mult Scler 2004, 10:472-474

32. Woo DA, Collins RH, Rossman HS, Stüve O, Frohman EM: Mitoxantroneassociated leukemia in multiple sclerosis: case studies. Int J MS Care 2008, 10:41-46.

33. Le-Page E, Leray E, Edan G, French Mitoxantrone Safety Group: Long-term safety profile of Mitoxantrone in a French cohort of 802 multiple sclerosis patients: a 5-year prospective study. Mult Scler 2011, 17:867-875.

34. Myasoedova E, Gabriel SE: Cardiovascular disease in rheumatoid arthritis: a step forward. Curr Opin Rheumatol 2010, 22:342-347.

35. Choi HK, Hernán MA, Seeger JD, Robins JM, Wolfe F: Methotrexate and mortality in patients with rheumatoid arthritis: a prospective study. Lancet 2002, 359:1173-1177.

36. Bernatsky S, Hudson M, Suissa S: Anti-rheumatic drug use and risk of hospitalization for congestive heart failure in rheumatoid arthritis. Rheumatology (Oxford) 2005, 44:677-680.

37. Myasoedova E, Crowson CS, Nicola PJ, Maradit-Kremers H, David JM 3rd, Roger VL, Therneau TM, Gabriel SE: The influence of rheumatoid arthritis disease characteristics on heart failure. J Rheumato/ 2011, 38:1601-1606.

38. Greenberg JD, Kremer JM, Curtis JR, CORRONA Investigators: Tumour necrosis factor antagonist use and associated risk reduction of cardiovascular events among patients with rheumatoid arthritis. Ann Rheum Dis 2011, 70:576-582

39. Jadidi E, Mohammadi M, Moradi T: High risk of cardiovascular diseases after diagnosis of multiple sclerosis. Mult Scler 2013. Jan 30. [Epub ahead of print].

40. Fleming ST, Blake RL Jr: Patterns of comorbidity in elderly patients with multiple sclerosis. J Clin Epidemiol 1994, 47:1127-1132.

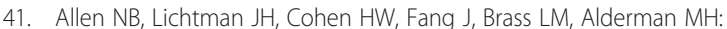
Vascular disease among hospitalized multiple sclerosis patients. Neuroepidemiology 2008, 30:234-238.

doi:10.1186/1471-2377-13-80

Cite this article as: Rivera et al:: Results from the 5-year, phase IV RENEW (Registry to Evaluate Novantrone Effects in Worsening Multiple Sclerosis) study. BMC Neurology 2013 13:80

\section{Submit your next manuscript to BioMed Central and take full advantage of:}

- Convenient online submission

- Thorough peer review

- No space constraints or color figure charges

- Immediate publication on acceptance

- Inclusion in PubMed, CAS, Scopus and Google Scholar

- Research which is freely available for redistribution 